\title{
Socioeconomic statuses across generations and coresidence in China
}

\author{
Jieming Chen ${ }^{1,2^{*}}$ and Qi Chen ${ }^{1}$
}

\author{
* Correspondence: \\ jmchen2010@mail.xjtu.edu.cn; \\ jmchen@tamuk.edu \\ 'Department of Sociology, Xi'an \\ Jiaotong University, Xi'an, China \\ ${ }^{2}$ Department of Psychology and \\ Sociology, Texas A\&M \\ University-Kingsville, Kingsville, TX, \\ USA
}

\begin{abstract}
The aim of this study is to investigate the influences of the socioeconomic status of both older parents and their children on coresidential living arrangements, hence the microlevel mechanism of the formation of coresidence, in order to trace the patterns of family change in China. Starting with the assumption that the extended family system is no longer a binding cultural ideal in China, this study formulates a new explanation that living arrangements between older parents and their adult children are influenced primarily by the economic resources of the two in that decisions on living arrangements reflect negotiations between the two generations, and economic benefits become the important factors in the decision-making process. Analyses of data from the 2010 wave of Chinese Family Panel Studies provide strong empirical support to the hypotheses derived from this conceptual framework. The results indicate that the more resources both parents and their adult children have, the less likely they will choose coresidence; conversely, the fewer the resources, the more likely they will choose coresidence. In addition, the analytical model is applicable to both rural and urban subsamples.
\end{abstract}

Keywords: Living arrangements, Coresidence, Socioeconomic status, Intergenerational relations

The living arrangement is one of the enduring research topics in anthropology, family sociology, and social demography (Yang 1959; Goode 1963; Parish and Whyte 1978; Fei 1983; Whyte and Parish 1984; Davis-Friedmann 1985, 1991; Tsui 1989; Logan et al. 1998; Guo 2002; Wang 2006; Feng 2009; Yang and Li 2009; Xie and Zhu 2009). The theoretical significance of this topic lies in the fact that living arrangements are part of family formation, are indicative of the way family life is conducted, and structurally determine interactions among family members, especially those between older parents and their grown children. By extension, as an important structural feature of family life, the living arrangement is an integral part of the basic organization of society (Goode 1963; Cohen 1976; Fei 1983, 1999).

Rapid economic development in China today is changing the way of life, including living arrangements. Population aging and massive rural-to-urban migration add more practical importance to the issue. Numerous studies have documented the connections between economic development and living arrangements. As social actors, how do grown children and their aging parents decide on their living arrangements? In other words, what is the microlevel mechanism of living arrangements? This is the question we seek to address in this study.

(C) 2016 The Author(s). Open Access This article is distributed under the terms of the Creative Commons Attribution 4.0 International License (http://creativecommons.org/licenses/by/4.0/), which permits unrestricted use, distribution, and reproduction in any medium, provided you give appropriate credit to the original author(s) and the source, provide a link to the Creative Commons license, and indicate if changes were made. 
Previous theory-oriented studies on living arrangements tend to adopt cross-cultural perspectives to investigate the differences and similarities of living arrangements under different cultural settings. Most of them use macrolevel concepts such as culture, history, or economic development to explain differentials in living arrangements (Goode 1963; Laslett 1972; Hajnal 1982; Goody 1990; Ruggles 2007). On the other hand, while providing valuable empirical results, most microlevel studies on living arrangements are relatively weak on theoretical explanations. As a result, few studies tackle the question of the microlevel mechanism of living arrangements, particularly that of intergenerational coresidence. This study seeks to take a first step in filling this void.

\section{Theories and research on living arrangements}

In general, theoretical explanations in regard to living arrangements are embedded in theories of family and population changes. The leading theoretical framework in family and population studies is modernization theory. The major theme of this theory is that industrialization and urbanization processes since the eighteenth century have brought about the reorganization of the basic structure of society, including the family system, namely the shift from so-called traditional society to modern society. ${ }^{1}$ Since modernization first occurred in Western societies, and because of the hidden paradigm of single linear development in the theory, changes that occurred in Western societies are always considered precursors of what will happen in non-Western societies that follow the West in the path of modernization (Inglehart 1997). ${ }^{2}$ In this sense, modernization also means westernization. Thus, the current family system in Western countries is often viewed as the end state of the transition of the family system in nonWestern countries. As to the issue of living arrangements, one conclusion that can be readily derived from the theory is the continuing decline of intergenerational coresidence (Parsons and Bales 1955; Goode 1963).

Of the sociologists who apply modernization theory and the related structural functionalism to the explanation of family changes, American sociologists Ernst Burgess and William J. Goode are two notable pioneers. Burgess proposes the emergence of the modern nuclear family and its crucial role in modern society for its emotionalsupportive functions; this proposition was further elaborated and advanced by other sociologists such as Ogburn and Parsons (Burgess 1916; Ogburn 1932; Parsons 1949; Bengtson 2001). Using similar dichotomous typology, Goode (1963) divides all families into conjugal families and traditional families based on the relative importance of parent-child and husband-wife relationships and suggests that all families will converge into conjugal families along with the modernization process. This theory is also known as the convergence theory. ${ }^{3}$

However, since the 1970s, a number of studies led by historians and social demographers, such as Lawrence Stone, Alan Macfarlane, and Peter Laslett, on European history of family and fertility changes, have cast doubt on the explanations offered by modernization theory. The basic conclusion of these studies is that European families possessed the defining attributes of modern families, that is, the nuclear family structure and low fertility rate, well before the advent of industrialization and urbanization (Laslett 1972; Shorter 1977; Stone 1980; Macfarlane 1986, 1987). According to their analysis, the changing path of the European family system as postulated by modernization theory simply did not exist. This suggests that the distinctions of various 
family patterns observed by comparative family studies may not be determined by different levels of economic development. The alternative is a cultural explanation. Moreover, two different kinds of family systems existed in the East and the West long before the industrial revolution (Hajnal 1982). This viewpoint can be termed "cultural explanations."

The two theories mentioned above represent two sets of interpretations of the specific historical facts from a macroscopic level. However, in regard to the microlevel mechanism of living arrangements, neither explanation has provided a systematic treatment. Methodologically, one of the common weaknesses of macrotheories is explaining macrolevel social phenomena with other macro phenomena and gloss over the microlevel causal mechanism in between, turning it into a "black box" (Coleman 1986; Hedström and Swedberg 1998; Goldthorpe 2006). The solution to this problem is to bring in social action theories and recognize that real individuals are active agents and the creators of all social reality. Microlevel theories such as rational choice and social exchange theories represent such an effort. Since the 1980s, researchers from various different academic backgrounds have conducted microlevel studies on family changes, especially familial reproductive behaviors (Caldwell 1976, 1982; Becker 1976, 1991). One common feature of these studies is that family members are considered social actors, and social phenomena about the family, including living arrangements, can be understood as the results of rational choices and social exchanges made by these actors under different structural constraints and different cultural conditions. Here, we call this approach the rational choice/social exchange theory of living arrangements.

According to modernization theory, living arrangements are determined by the level of economic development. Along with economic development, family systems from different societies would gradually converge to the nuclear family pattern seen in present Western societies. However, according to the cultural explanations, different living arrangements always existed in different societies and were not necessarily determined by economic development. For instance, long before the advent of the industrial revolution, the nuclear family was the dominant family structure in Western Europe (Shorter 1977). The rights and obligations inherent in intergenerational relations in the Western family system are completely changed after grown children "leave the nest." In broad strokes, grown children do not have the responsibility of supporting their aging parents, and any possible long-term economic relationships between the two generations tend to be explicitly contractual (Macfarlane 1986). In contrast, while parent-child relations in the traditional Chinese family system also change significantly after children come of age, grown sons share the responsibility of supporting their older parents (Yang 1959; Fei 1983).

The rational choice/social exchange theory stresses the mechanisms of formation and operation of family institutions, including that of living arrangements, from the perspective of social actors. This theoretical tradition does not deny the importance of macrolevel structural and cultural conditions but contends that all macrolevel factors exert their impact through social actors. The formation and maintenance of a social institution are accomplished through the actions and interactions of real individuals capable of making rational and deliberate decisions (Goldthorpe 2006). Thus, it is the interactions, negotiations, and exchanges that happen between two generations within numerous concrete families that result in a particular pattern of living arrangements. 
Older parents and their grown children jointly make the decision about whether to coreside, constrained by social conditions and guided by cultural norms.

Under the general conditions in China today with its cultural tradition of familism and filial piety, no matter how diluted, and the economic structure of a mixture of market economy and a socialist redistributive system, how do Chinese parents and their grown children make their decisions about coresidence? Empirical studies have made significant contributions and advancements. Some stress the importance of cultural norms and family structure on living arrangements. For instance, Guo (2002) finds that aged parents had a strong preference for living with a son to a daughter, which was apparently consistent with the traditional patrilocal norms. However, Feng (2009) points out that the patrilocal preference was rapidly fading under the demographic constraints of the one-child family structure. For example, in families with more than one child the probability of older parents living with their sons is higher than with their daughters. However, in families with only one child, parents have a much higher chance of coresiding with their daughters. $\mathrm{Xu}$ (2013a) also suggests that in urban areas where the one-child policy has been more stringently followed, aged parents are more likely to live with a daughter as a replacement for a son.

Aside from the consideration of the impact of cultural norms, an increasing number of empirical studies have focused on the roles of economic logic and personal choice in living arrangements. Logan and Bian (2003) find that there is inconsistency between preference and practice as to older people's living arrangements. Some older parents who prefer to living independently may have to choose to live with their children simply because of a housing shortage on the part of the children, whereas other older parents may be forced to live apart from their grown children because there is inadequate space for two or three generations to live under one roof, even though these parents would like to live with their married children. Therefore, the coresidence that seems to conform to traditional values may not be chosen out of a concern with tradition. When making a living arrangement decision, people appear to care more about the actual benefits to their daily life rather than whether their arrangements are consistent with traditional norms. In a study of factors that may influence the coresidence decision, $\mathrm{Xu}$ (2013b) puts the emphasis on the children's needs. Young couples who are just stepping into the workplace may benefit from coresidence with their parents due to it reducing a certain amount of daily expenses and obtaining parents' help in housework and/ or childcare. As a result, adult children with poor economic conditions such as low income or poor housing are more likely to live with their parents. A study by Logan and his colleagues (Logan et al. 1998) suggests that the multigenerational family household, a traditional ideal in the past, is no longer viewed as the ideal living arrangement today. Most aged parents and their adult children in urban areas prefer independent living. Xie and Zhu (2009) point out that in cities, the support that grown children provide to their aging parents, including the arrangement of coresidence, is more important for its symbolic meaning than for functional purposes.

The empirical studies discussed investigate the familial old-age support system in contemporary China from different angles. A common theme that emerges from these studies is the decline of the Chinese traditional family system. As to intergenerational living arrangements, there is clear evidence that multigenerational extended family households are no longer a binding cultural ideal. 


\section{Mechanisms of economic gains and family obligations: the theoretical frame- work and hypotheses}

The term "coresidence" is used here to refer to an intergenerational coresidential living arrangement in which aged parents live together with their adult children, forming a corporate group with respect to contact frequency, resource sharing, and emotional attachment. When older parents and married children live in a single household, coresidence can also be understood as the joining of two family units.

Coresidence entails the sharing of resources. As such, the choice of whether to coreside clearly involves consideration of economic factors. At the macro level, coresidence, measured by the coresidence rate, is influenced by structural conditions such as population structure, cultural norms, and social and economic conditions (Goldscheider and Goldscheider 1989; Logan et al. 1998; Ruggles 2007; Ruggles and Heggeness 2008). ${ }^{4}$ According to the cultural explanations, the way family life is conducted reveals the basic value orientations of a society. Although the arrangement in which a family is a unit where children are raised is universally practiced, with respect to the choice of living arrangements-whether married children choose a patrilocal residence, a matrilocal residence, or an independent residence, it varies greatly in different cultural settings (Hajnal 1982). The tradition calls for parents to coreside with their adult children, primarily with a son. However, although many older parents today still live with their married children, the norm of filial piety, the key component of the traditional culture that long governed family life and included the appeal of coresidence, is losing its normative potency. When coresidence as a personal pursuit is no longer a powerful cultural ideal and as a norm is no longer a cultural imperative, it can be inferred that economic benefits, or in a general sense economic costs and benefits, will be a major factor that determines whether to coreside.

The decision of coresidence involves two generations: the aging parents and their adult children. Before the decline of parental power in the traditional family system, the decision rights on living arrangements was, at least in an ideal situation, firmly in the hands of the parental generation. ${ }^{5}$ According to modernization theory, the modernization process significantly weakened the authority of older parents. The economic function of the family as a production unit has withered, as has the parental power that is based on the control of family property. Children coming of age can quickly gain their economic independence, and because of the division of labor, technological advancements in the modern economy, and expansion of educational opportunities, the younger generation's earning potential tends to be higher than that of the older one (Cowgill 1972). All these changes directly or indirectly result in a decline of parents' authority, including the decision-making on intergenerational living arrangements. When the decision-making process involves both generations rather than the parent generation alone, economic considerations from both become important factors in the decision.

The main advantage of coresidence lies in the sharing of resources and the improvement of total economic gains, but at the cost of worsening housing conditions, lack of privacy, restrictive family relations, increased family disputes, and management costs (Fei 1999). Coresidence is an appealing arrangement for both parents and children when both are economically disadvantaged. For parents, especially those who are widowed or who lack their own independent and stable income, coresidence with their 
children is often the only choice in order to maintain a normal life. As for the children, when they are too economically constrained to provide old-age support to their parents in other ways such as sending cash or in-kind gifts, coresidence not only is the most cost-effective way for them to provide old age support but also enables them to obtain some help in housework and childcare from their parents if their physical condition permits. On the other hand, when both older parents and their children are well off, coresidence loses its economic attractiveness due to increased opportunity costs. If they are in need of support for household chores or personal care, both older parents and adult children of higher socioeconomic status can afford to purchase such services from the market as a substitute for the benefits they might receive from coresidence.

However, it should be recognized that coresidence is a specific family combination owing to the mutual commitments in the parent-child relationship. Coresidence does not always benefit both parents and children at the same time. Because of resource sharing, coresidence implies equalization of resources to a certain degree, no matter how the resources are allocated or managed in the joint family. When the economic conditions of parents and their adult children differ substantially, equalization means transfer of economic resources from one generation to the other. The more substantial the differences are, the greater the transfer of resources. As a result, economic logic would not be the driving force for both generations. The side with poor socioeconomic conditions would expect to obtain economic gains through coresidence, while the side with better conditions would have less economic incentive but would be motivated to choose coresidence out of a sense of obligation (Chen 2010; Yang and He 2004). Because of the mutual obligations inherent in the parent-child relationship and the commitments cultivated by parents through years of effort, both parents and children are deeply concerned about each other's welfare as well as their own. Thus, in the case of a significant intergenerational gap in socioeconomic status, the sense of family obligation plays a role in which the economically advantaged side endures certain losses and offers coresidence as a way of providing support, and the economically disadvantaged side accepts the offer of support and agrees to coresidence.

Coresidence symbolizes provision of familial support across generations. When coresiding adult children are significantly better off than their parents financially, coresidence carries the meaning of old age support. When the parents are better off than the children, coresidence implies parents' continued help or investment in their children (Chen 1998). In sum, if the two generations only take each side's benefits into consideration when deciding whether to live together, coresidence will not occur if only one side benefits. On the other hand, when each generation is also concerned about the other's well-being, coresidence will occur even if one generation will incur certain economic loss.

It should be pointed out that the discussions above are analytical in nature. In addition to resource sharing, coresidence promotes mutual assistance in household chores and emotional support across generations. Therefore, coresidence may also imply the exchange between transfer of economic resources and assistance in housework between the two generations. Even with these factors taken into consideration, our basic analytical line of reasoning still holds, namely that the choice for coresidence involves two generations, coresidence represents mutual assistance between two generations, and it can still occur even in the case of substantial differences in socioeconomic status between the generations. 
In sum, we argue that the choice to coreside is based on economic considerations and family obligations by both the older parent and grown children generations. When both generations are economically disadvantaged, the benefits of economies of scale along with family obligations drive them to choose coresidence. When there is a significant gap in socioeconomic positions between two generations, economic factors and family obligation play different roles. The economically advantaged side is motivated by commitment to family obligation while the disadvantaged side gains economic benefits from coresidence. In this case, since the logic for choosing coresidence differs between the generations, the driving force that compels them to choose coresidence is not as strong as when both sides are disadvantaged. Lastly, when both parents and adult children are economically well off, the gains from economic resource sharing fail to offset the opportunity cost of coresidence and the call to provide family support loses its urgency, leading to the lowest possibility of coresidence. The economic conditions of older parents and adult children are likely to have additive effects on the living arrangement of coresidence.

According to the above discussions, we put forward the following hypotheses:

Hypothesis 1: Other things being equal, the higher the older parents' socioeconomic status, the less likely that they will live with their adult children. Conversely, the lower their socioeconomic status, the more likely they will choose coresidence.

Hypothesis 2: Other things being equal, the higher the adult children's socioeconomic status, the less likely that they will live with their older parents. Conversely, the lower their socioeconomic status, the more likely they will choose coresidence.

Based on $\mathrm{H} 1$ and $\mathrm{H} 2$, it can be further hypothesized that when the socioeconomic statuses of both older parents and children are low, they are most likely to choose coresidence; when the socioeconomic statuses of both are high, they are least likely to choose coresidence.

\section{Data, variables, and analytic strategy \\ Data}

The data used in this analysis were drawn from the initial wave of the Chinese Family Panel Study (hereafter CFPS2010), a major national survey on family life in China conducted in 2010 by the Institute of Social Science Survey (ISSS) of Peking University. The survey adopted a stratified multistage area probability-sampling frame that covered 25 provinces, autonomous regions, and province-level municipalities of the country. The resulting samples consist of 14,960 family households and all adult members of the households. ${ }^{6}$

Since our focus is living arrangements between aged parents and their adult children, we restricted our analysis to the cases of family households containing at least one member aged 60 or above from the family data set, then merged the data with that of corresponding parents and children from the adult data sets. The resulting study sample consisted of 4471 cases, comprised of 2372 from rural areas and 2099 from cities. The study sample included 3055 cases in which both older parents were alive and 1416 cases in which only one parent was alive (968 widows and 448 widowers). It should be stressed that the units of analysis were not older parents but families containing both parents aged 60 or above and their children (including those not coresiding), to be precise, parent-child collectives. 
Since CFPS2010 employed the implicit stratified multistage sampling and oversampled five provinces/municipalities-Shanghai, Liaoning, Henan, Gansu, and Guangdong-weighting was needed. All analyses reported in this study were weighted to take oversampling, complex survey design, and poststratification adjustment into consideration.

\section{Variables}

The dependent variable in our study is whether parents aged 60 or above coresided with their adult children. It is a dichotomous variable with two values: 1 indicates coresidence, and 0 represents no coresidence.

The focus of this study is to examine the impact of parents' and children's socioeconomic statuses on the living arrangement of coresidence. Socioeconomic status is a multidimensional concept, and its measurement is rather complex. We employed the variables of education, income, and occupational prestige as its indicators. Given the limitation of the data, the parents' socioeconomic status is captured by two variables, including parents' educational level and income. The coding of the variable of parents' educational level is as follows. If both parents were alive, we chose the higher level of education of the two as a proxy of parents' education, then constructed a dummy variable with two values: $1=$ high education and $0=$ low education, with the sample mean (3.97 years) as the dividing point. Parents' income variable was coded in a similar way. If both parents were alive, we chose the average, and then used the sample mean (6698 yuan per year) as a point of division to assign income as high or low. Since some parents had no income, the resulting income had three values: high, low, and no income. We adopted the above coding methods for the simple reason that the original distributions of the variables are highly skewed while the categorical variables more clearly reveal the effects on intergenerational coresidence.

For the same reason of data limitation, children's socioeconomic status was assessed by children's educational level and the International Socioeconomic Index (ISEI) to measure occupation. ${ }^{7}$ Since we sought to use these two variables to gauge the status of all children, including those not coresiding, the coding process was also rather complicated. Two steps were taken to create these variables. First, for households with coresident children, if there was only one coresident child the child's education and ISEI were used; if there were two or more coresiding children, the averages were used. For households with no coresiding children the averages of education and ISEI of these children were used. Second, the sample means of these two variables (10.67 and 35.05) were used as the cutoff points to assign values of either high or low to each variable. In the questionnaire, if a grown child did not have a job or the job category could not be determined, a missing value was assigned. There were 1122 cases that had such missing values for the variable of ISEI. To keep these cases for analysis, we assigned the value as "other" in the ISEI variable.

Other variables that were used as controls in the analyses include older parents' age, marital status, self-rated health, whether at least one son was alive, a daughter alive, whether children were single, size of house, living in an urban area, and opinion on some traditional values. The use of older parents' age in multivariate analysis is to control the parents' changing needs because of increased age. The age variable was coded 
in the following way. If both father and mother were alive in 2010, we took the older one's age as a proxy for parents' age. If only one parent was alive, we used his or her age. Marital status indicates whether or not the parents or parent was currently married. For the same reason, this variable was used to take into consideration old parents' differing needs caused by change in marital status. Self-rated health condition is another variable that measured parents' needs. It was coded into three categories: good, fair, and poor. If both parents were alive, the condition of the less-healthy one was chosen. The variable of whether parents had a son or daughter alive partly measures the demographic condition of coresidence. The variable of whether they had an unmarried child indicates the nature of coresidence. Our definition included not only a child who was still unmarried but also a child who was divorced or widowed in 2010. The size of house described housing condition. The residence was measured by a dummy variable indicating whether the household was located in a city or a rural area. This variable was also used to divide the sample into urban and rural samples for separate analysis.

Lastly, we also included a composite attitudinal variable to control for the effect of traditional ideas. From a section of the questionnaire that contains a number of attitudinal questions on values, we selected three items to assess the extent to which parents held traditional values on family life. These three items were: "Do you think it is important to be remembered by people after death?" "Do you think it is important to have offspring to carry on your family name?" and "Do you think it is important for children to succeed in life?" Preselected responses ranged from "1. not important at all" to "5. very important." The composite variable is the sum of the answers to these three questionnaire items, with scores ranging from three to 15 and higher values indicating more traditional attitudes. ${ }^{8}$

The basic characteristics of the dependent variable and four major independent variables for the whole sample and by residence are given in Table 1. The information of other variables is not presented due to space limitations.

\section{Analytic strategy}

To illustrate the association between parents' and children's socioeconomic status and the living arrangement of coresidence, we conducted contingency table analysis and logistic regression analysis. In consideration of the differences between cities and rural areas with regard to economic development, welfare policies on old age, and pension distribution, and therefore different ways that resources across generations influence living arrangements, we conducted analyses of urban and rural subsamples separately.

Three specific steps were taken in the data analysis. First, using the contingency table analysis method, we analyzed the relationship between the socioeconomic status of both generations and coresidence. Second, we employed the logistic regression model to conduct multivariate analyses. Lastly, using the results from our multivariate analyses, we computed predicted probabilities of coresidence under different combinations of parents' and children's social economic statuses.

The prediction equation of binary logit regression model can be written as:

$$
\ln \left(\frac{\hat{p}_{i}}{1-\hat{p}_{i}}\right)=\sum_{k=0}^{K} \hat{\beta}_{k} x_{i k}
$$


Table 1 Basic characteristics of main variables (weighted)

\begin{tabular}{|c|c|c|c|c|c|c|}
\hline & \multicolumn{2}{|c|}{ Rural subsample } & \multicolumn{2}{|c|}{ Urban subsample } & \multicolumn{2}{|c|}{ Whole sample } \\
\hline & Frequency & Percentage & Frequency & Percentage & Frequency & Percentage \\
\hline \multicolumn{7}{|l|}{ Living arrangement } \\
\hline Does not coreside & 842 & 35.49 & 907 & 43.21 & 1748 & 39.09 \\
\hline Coreside & 1530 & 64.51 & 1192 & 56.79 & 2723 & 60.91 \\
\hline \multicolumn{7}{|l|}{ Parents' education ${ }^{a}$} \\
\hline $\operatorname{Low}(<3.97$ years) & 1645 & 69.36 & 1026 & 48.88 & 2675 & 59.82 \\
\hline High( $\geq 3.97$ years) & 727 & 30.64 & 1073 & 51.12 & 1796 & 40.18 \\
\hline \multicolumn{7}{|l|}{ Parents' income ${ }^{b}$} \\
\hline No income & 456 & 19.21 & 529 & 25.20 & 984 & 22.0 \\
\hline Low(<6698 yuan) & 1638 & 69.06 & 852 & 40.57 & 2494 & 55.78 \\
\hline High( $\geq 6698$ yuan) & 278 & 11.73 & 718 & 34.23 & 993 & 22.22 \\
\hline \multicolumn{7}{|l|}{ Children's educaiton ${ }^{c}$} \\
\hline Low(<10.67 years) & 1325 & 55.86 & 854 & 40.68 & 2181 & 48.78 \\
\hline $\operatorname{High}(\geq 10.67$ years $)$ & 1047 & 44.14 & 1245 & 59.32 & 2290 & 51.22 \\
\hline \multicolumn{7}{|l|}{ Children's ISEI ${ }^{c}$} \\
\hline $\operatorname{Low}(<35.05)$ & 1503 & 63.36 & 718 & 34.22 & 2225 & 49.77 \\
\hline $\operatorname{High}(\geq 35.05)$ & 380 & 16.04 & 746 & 35.54 & 1124 & 25.13 \\
\hline Others & 488 & 20.59 & 635 & 30.24 & 1122 & 25.09 \\
\hline
\end{tabular}

Source of data: CFPS2010

a If both parents were alive, the higher one was used

${ }^{b}$ If both parents were alive, the average was used

c If there were more than two non-coresident children, the averages were used

where $i=1,2,3 \ldots n$ indicates the cases; $k=0,1,2,3 \ldots K$ indicates number of independent variables; $x_{k}$ is the $k$ th independent variable; $\hat{\beta}_{k}$ indicates the estimated coefficient for variable $x_{k}$; and $\hat{p}_{i}$ is the predicted probability. With simple algebraic manipulation, we get:

$$
\hat{p}_{i}=\frac{\exp \left(\sum_{k=0}^{\mathrm{K}} \hat{\beta}_{k} x_{i k}\right)}{1+\exp \left(\sum_{k=0}^{\mathrm{K}} \hat{\beta}_{k} x_{i k}\right)}
$$

The formula was used to compute predicted probabilities of coresidence under different combinations of parents' and adult children's socioeconomic statuses.

\section{Results}

\section{Basic description of main variables}

The descriptive analyses (weighted) presented in Table 1 show that coresidence is still the main living arrangement for older parents. In the whole sample, about $61 \%$ of parents aged 60 or above coresided with their children. In the urban and rural subsamples, the percentages are about 65 and $57 \%$, respectively. The results are very close to that obtained at the end of the twentieth century (Logan et al. 1998; Yan et al. 2001; Guo 2002), suggesting that the pattern of coresidence has remained largely unchanged over the past two decades. ${ }^{9}$

As discussed above, we used parents' education and income to measure parents' socioeconomic status and children's education and ISEI to capture children's socioeconomic status. For older parents, those living in rural area were apparently 
disadvantaged compared with their counterparts in urban areas. For example, in rural areas, nearly $70 \%$ of older parents had years of education below the average; in comparison, in cities, this percentage was less than half that number.

The pattern is the same with respect to rural and urban differences in children's socioeconomic status. Children living in cities were clearly advantaged vis-à-vis their counterparts living in rural areas. Whereas the percentage of the children in rural areas whose years of education were below the average was $56 \%$, it was only $41 \%$ in urban areas.

There are two major features that are worth noting when comparing older parents and their grown children. First, there was an overall improvement in educational attainment from parents to children. The average number of years of education for parents was 4 years but about 11 years for children. Second, the rural and urban gap in socioeconomic status remains fairly large. For instance, the proportion of children who were in the lower group of ISEI in rural areas was $63 \%$ and only $33 \%$ in urban areas.

\section{Bivariate analyses of coresidence}

The results of bivariate analysis between parents' and children's socioeconomic statuses and coresidential living arrangement are presented in Table 2.

The results show that the lower the parents' education and income, the higher the proportion of coresidence with their children. A similar relationship exists between children's socioeconomic conditions and coresidence. Overall, the higher the socioeconomic statuses of both parents and their children, the lower the proportion of coresidence between the two generations. Statistical tests indicate that except for that between children's education and coresidence, all the relationships are statistically significant.

Almost the same patterns are found in the urban subsample. Among older parents, those with lower education have a higher proportion of coresidence than those of higher education (63 and $51 \%$, respectively); those with no income or low income have a higher proportion of coresidence than those with higher income $(62,58$, and $52 \%$, respectively). Among grown children, those in the lower education and ISEI categories tend to have a higher proportion of coresidence than those in the higher categories. Except for parents' income, the other three variables have a significant effect on coresidence.

The results of the contingency table analysis provide support for both hypothesis 1 and hypothesis 2 for both the rural and urban subsamples. Despite the differences in economic development and public services between rural areas and cities, as reflected at the individual level the differences in socioeconomic statuses, the mechanism discussed in the previous section appears to be applicable in both rural and urban areas; that is, for both older parents and their grown children, those who chose coresidence had less economic resources than those who lived independently.

\section{Multivariate analyses}

The bivariate analyses presented above describe the relationship between each single explanatory variable and the variable of coresidence without controlling other relevant variables and without answering the question of the extent to which the parents' and children's socioeconomic resources had an impact on the living arrangements. To 
Table 2 Bivariate analysis of socioeconomic statuses of parents and children and coresidence by residence (percentage, weighted)

\begin{tabular}{|c|c|c|c|c|}
\hline \multicolumn{5}{|l|}{ Rural areas } \\
\hline \multirow[t]{2}{*}{ Independent variables } & \multicolumn{3}{|l|}{ Living arrangements } & \multirow[t]{2}{*}{ F-test } \\
\hline & Non-coresidence & Coresidence & Total & \\
\hline Parents' education & & & & $12.47^{* * * *}$ \\
\hline Low & 31.85 & 68.15 & 100.00 & \\
\hline High & 43.73 & 56.27 & 100.00 & \\
\hline Parents' income & & & & $12.90^{* * * *}$ \\
\hline No income & 25.26 & 74.74 & 100.00 & \\
\hline Low & 35.91 & 64.09 & 100.00 & \\
\hline High & 49.82 & 50.18 & 100.00 & \\
\hline Children's education & & & & 0.51 \\
\hline Low & 34.52 & 65.48 & 100.00 & \\
\hline High & 36.73 & 63.27 & 100.00 & \\
\hline Children's ISEI & & & & $16.18^{* * * *}$ \\
\hline Low & 34.67 & 65.33 & 100.00 & \\
\hline High & 53.44 & 46.56 & 100.00 & \\
\hline Others/missing & 23.65 & 76.35 & 100.00 & \\
\hline \multicolumn{5}{|l|}{ Urban areas } \\
\hline \multirow[t]{2}{*}{ Independent variables } & \multicolumn{3}{|l|}{ Living arrangements } & F-test based on design effect \\
\hline & Non-coresidence & Coresidence & Total & \\
\hline Parents' education & & & & $13.43^{* * * *}$ \\
\hline Low & 36.99 & 63.01 & 100.00 & \\
\hline High & 49.15 & 50.85 & 100.00 & \\
\hline Parents' income & & & & $2.47^{*}$ \\
\hline No income & 38.41 & 61.59 & 100.00 & \\
\hline Low & 41.72 & 58.28 & 100.00 & \\
\hline High & 48.50 & 51.50 & 100.00 & \\
\hline Children's education & & & & $10.61^{* * * *}$ \\
\hline Low & 37.33 & 62.67 & 100.00 & \\
\hline High & 47.24 & 52.76 & 100.00 & \\
\hline Children's ISEI & & & & $21.10^{* * * *}$ \\
\hline Low & 37.27 & 62.73 & 100.00 & \\
\hline High & 57.28 & 42.72 & 100.00 & \\
\hline Others/missing & 33.21 & 66.79 & 100.00 & \\
\hline
\end{tabular}

${ }^{*} p<0.1 ;{ }^{* *} p<0.05 ;{ }^{* * *} p<0.01 ;{ }^{* * * *} p<0.001$

accomplish such tasks, we employed logit regression models to control related covariates and observe whether and how the economic resources of the two generations influence living arrangements. Specifically, we introduced parents' and children's economic resources into the equations separately ("parents' resources model" and "children's resources model") to discover the magnitudes of the influences on coresidence. We then put the resources of both generations in the equation at the same time ("parent-child resources model"). Lastly, we added all control variables into the equation ("full model") to determine whether the effects of parents' and children's resources variables were still significant. 
Table 3 presents the results of the four models. It is clear from the "parents' resources model" that the more economic resources older parents possess, the less likely it is that they will live with their children. The odds that parents in the no-income or lowincome categories will live with their children are about 1.8 and 1.4 times as much as parents in the high-income group. Similarly, the odds ratio of coresiding parents in the low-education category with those in the high-education group is 1.6. Most variables are still statistically significant when variables about children are added into the equation.

In the children's resources model, the way children's resources impacted the occurrence of coresidence is about the same as the parents' resources. For example, the odds ratio of children in the low-ISEI group is $2.2(p<0.001)$, suggesting they

Table 3 Logit regressions of intergenerational resources on coresidence (odds ratio)

\begin{tabular}{|c|c|c|c|c|}
\hline & $\begin{array}{l}\text { Parents' resources } \\
\text { model }\end{array}$ & $\begin{array}{l}\text { Children's resources } \\
\text { model }\end{array}$ & $\begin{array}{l}\text { Parent-children } \\
\text { resources model }\end{array}$ & Full model \\
\hline \multicolumn{5}{|l|}{ Parents' income (ref: high) } \\
\hline No income & $1.811(.276)^{* * * *}$ & & $1.813(.280)^{* * * *}$ & $1.856(.286)^{* * * *}$ \\
\hline Low & $1.365(.176)^{* *}$ & & $1.286(.173)^{*}$ & $1.215(.163)$ \\
\hline Parents' education (ref: high) & $1.629(.179)^{* * * *}$ & & $1.435(.165)^{* * *}$ & $1.292(.158)^{* *}$ \\
\hline \multicolumn{5}{|l|}{ Children's ISEI (ref: high) } \\
\hline Low & & $2.204(.275)^{* * * *}$ & $1.970(.252)^{* * * *}$ & $1.930(.232)^{* * * *}$ \\
\hline Others/missing & & $2.982(.414)^{* * * *}$ & $2.831(.399)^{* * * *}$ & $3.033(.442)^{* * * *}$ \\
\hline Children's education (ref: high) & & $1.151(.114)$ & $1.112(.114)$ & $1.010(.109)$ \\
\hline \multicolumn{5}{|l|}{ Parents' age (ref: 60-64) } \\
\hline $65-69$ & & & & $.818(.103)$ \\
\hline $70-74$ & & & & $.623(.082)^{* * * *}$ \\
\hline $75-79$ & & & & $.527(.078)^{* * * *}$ \\
\hline $80-110$ & & & & $.813(.178)$ \\
\hline \multicolumn{5}{|l|}{ Parents' marital (ref: in marriage) } \\
\hline Widowed mother & & & & $2.701(.343)^{* * * *}$ \\
\hline Widowed father & & & & $1.645(.259)^{* * *}$ \\
\hline Having an alive son (ref: none) & & & & $1.891(.313)^{* * * *}$ \\
\hline $\begin{array}{l}\text { Having an alive daughter (ref : } \\
\text { none) }\end{array}$ & & & & $.756(.105)^{* *}$ \\
\hline Having a single child (ref : none) & & & & $3.835(.474)^{* * * *}$ \\
\hline Size of housing & & & & $1.007(.001)^{* * * *}$ \\
\hline \multicolumn{5}{|l|}{ Parents' self-rated health (ref: good) } \\
\hline Fair & & & & $1.126(.118)$ \\
\hline Poor & & & & $1.103(.142)$ \\
\hline Traditional attitude & & & & $1.064(.023)^{* * *}$ \\
\hline Residence (ref: rural) & & & & $1.051(.141)$ \\
\hline Constant & $.868(.104)$ & $.758(.076)^{* * * *}$ & $.511(.072)^{* * * *}$ & $.060(.025)^{* * * *}$ \\
\hline F-test & $12.39^{* * * *}$ & $26.91^{* * * *}$ & $17.01^{* * * *}$ & $18.01^{* * * *}$ \\
\hline$n$ & 4471 & 4471 & 4471 & 4471 \\
\hline
\end{tabular}


are twice as likely to live with their older parents as those in the high-ISEI group. Though not significant, the odds ratio of adult children with lower education level is 1.15 .

Finally, we added control variables such as parents' age and marital status to construct a full model. The results show that most socioeconomic variables are still significant except for children's education. Parents in the no-income group are 1.9 times as likely to live with their children as those in the high-income group (OR = $1.9, p<0.001)$. The odds ratio of the low-education group compared to the higheducation group drops to 1.29 , suggesting parents with a low education level have a $29 \%$ higher likelihood of living with children than parents with a high education level. Children's ISEI is still significant in the full model.

Let us turn to the impact of control variables. We categorized parents' age into five groups to investigate the possible nonlinear relationship between age and living arrangements. The results suggest that there is indeed a U-shaped nonlinear association. The chance of coresidence decreases as parents' age increases until the age of 80 and then begins to go up. This may reflect the changes in parents' familial responsibility in the family's life cycle. When older parents are relatively young, they may have children who are still single or are facing the dual burden of developing their career and raising their own children and are thus in need of support from their older parents for child care or housework. As children move into middle age, they and their older parents may prefer to have independent living if possible, leading to a decrease in coresidence. However, when parents get into advanced old age, children may choose to live with their parents so as to provide care, leading to a rebound of the coresidence rate.

In addition, there is a strong significant relationship between older parents' marital status and coresidence, as documented in previous studies. Widowed or divorced older parents are much more likely to live with their children. Our results show that a widowed or divorced father is 1.6 times as likely to coreside with his children as married parents. For a widowed or divorced mother, the odds are as high as 2.7 times. Under these situations, coresidence clearly indicates old-age support for the parents.

Our bivariate analyses show that while the basic pattern of influence of intergenerational resources on coresidence is similar in both urban and rural areas, some variations do exist, suggesting the existence of different mechanisms. Thus, we fitted the full model on urban and rural subsamples separately. The results are reported in Table 4.

The results in Table 4 indicate that some slight differences exist in the effects of intergenerational resources on coresidence between urban and rural areas. First, parents' income has a greater impact on coresidence in rural areas than in urban areas. In rural areas, parents with no income or low income are 2.7 and 1.7 times as likely to coreside with their children as parents with high income. In urban areas parents with no income are 1.6 times as likely to coreside with their children as parents with high income, and the difference between parents with low income and parents with high income is not statistically significant. Children's education has no influence on coresidence. Parents' education has the same impact in both urban areas and rural areas. 
Table 4 Logit regressions of intergenerational resources on coresidence by residence

\begin{tabular}{|c|c|c|c|c|}
\hline & \multicolumn{2}{|l|}{ Rural areas } & \multicolumn{2}{|l|}{ Urban areas } \\
\hline & Odds ratio & SE & Odds ratio & SE \\
\hline \multicolumn{5}{|l|}{ Parents' income (ref: high) } \\
\hline No income & $2.725^{* * * *}$ & .218 & $1.550^{* *}$ & .202 \\
\hline Low & $1.656^{* * *}$ & .177 & 1.012 & .206 \\
\hline Parents' education (ref: high) & $1.317^{*}$ & .165 & $1.312^{*}$ & .163 \\
\hline \multicolumn{5}{|l|}{ Children's ISEI (ref: high) } \\
\hline Low & $2.050^{* * * *}$ & .186 & $1.902^{* * * *}$ & .167 \\
\hline Others/Missing & $3.574^{* * * *}$ & .266 & $2.774^{* * * *}$ & .166 \\
\hline Children's education (ref: high) & 1.018 & .144 & 1.064 & .163 \\
\hline \multicolumn{5}{|l|}{ Parents' age (ref: 60-64) } \\
\hline $65-69$ & $.710^{* *}$ & .156 & 1.034 & .185 \\
\hline $70-74$ & $.585^{* * *}$ & .177 & $.683^{*}$ & .204 \\
\hline $75-79$ & $.587^{* *}$ & .207 & $.476^{* * * *}$ & .191 \\
\hline $80-110$ & .650 & .324 & 1.034 & .234 \\
\hline \multicolumn{5}{|l|}{ Parents' marital (ref: in marriage) } \\
\hline Widowed mother & $3.410^{* * * *}$ & .211 & $2.145^{* * * *}$ & .150 \\
\hline Widowed father & $1.621^{* * *}$ & .184 & $1.755^{*}$ & .287 \\
\hline Having an alive son (ref: none) & $2.559^{* * * *}$ & .222 & $1.515^{*}$ & .219 \\
\hline Having an alive daughter (ref: none) & .845 & .210 & $.666^{* *}$ & .191 \\
\hline Having a single child (ref: none) & $3.700^{* * * *}$ & .166 & $4.178^{* * * *}$ & .171 \\
\hline Size of housing & $1.007^{* * * *}$ & .001 & $1.008^{* * * *}$ & .001 \\
\hline \multicolumn{5}{|l|}{ Parents' self-rated health (ref: good) } \\
\hline Fair & 1.067 & .168 & 1.172 & .139 \\
\hline Poor & .882 & .164 & $1.500^{* *}$ & .188 \\
\hline Traditional attitude & 1.049 & .033 & $1.094^{* * *}$ & .029 \\
\hline Constant & $.043^{* * * *}$ & $.623^{* * * *}$ & $.055^{* * * *}$ & .473 \\
\hline F-test & $14.2^{* * * *}$ & & $12.46^{* * * *}$ & \\
\hline$n$ & 2372 & & 2099 & \\
\hline
\end{tabular}

\section{Predicted probabilities of coresidence}

To illustrate the results obtained from the regressions above in a more direct way, we categorized parents' and children's resources into three groups (high, middle, and low), then calculated the probabilities of coresidence of nine combinations of parents' and children's resources based on the results reported in Table 4. We employed parent's income and education to measure parents' economic resources and employed children's ISEI and education to assess children's economic resources. The division criteria are as follows. We assigned those parents who were in both the high-income group and higheducation group into the "high-resources group," those parents who were in both the low-income group (or no-income group) and low-education group into the "low-resources group," and the remainder into the "middle-resources group." Similarly, we assigned those children who were in both the high-ISEI group and the high-education group into the "high-resources group," those children who were in both the low-ISEI group and low-education group into the "low-resources group," and the remainder into the "middle-resources group." 
The predicted probabilities in all combinations of economic resources are listed in Table 5. The average predicted probability of coresidence in rural areas is 0.617 , and 0.527 in cities, suggesting that, other things being equal, parents living in rural areas are more likely to live with their children than those in cities. However, the patterns of the influence of economic resources across generations are quite similar in both rural and urban areas. After controlling children's resources, the probability of coresidence increases as parents' resources decrease in both rural areas and cities. Likewise, with parents' resources controlled, the probability of coresidence increases as children's resources decrease.

When both parents' and children's resources are considered simultaneously, the differences in predicted probabilities among different combinations are even greater. For instance, for the urban subsample, the probability of the combination of parents in high-resources group and children in the high-resources group is 0.353 . In comparison, the probability of a "low-low" combination is 0.691 , about two times that of the "highhigh" combination.

Using parents' income and education, and children's international socioeconomic index and education as predictors, we employed bivariate and multivariate analyses to investigate the impact of parents' and children's economic resources on the living arrangement of coresidence. The statistical results provide strong support for the association between them. Both hypothesis 1 and hypothesis 2 are empirically supported by our analysis results. Furthermore, separate analyses on rural and urban subsamples suggest that the mechanism explicated in the second section of this article applies to both rural areas and cities.

\section{Summary and discussion}

In the study of family residential patterns, coresidence between adult children and their older parents is of particular theoretical importance. A particular living arrangement that families may choose is molded by the dominant cultural norms in society, gradually forming a habitus and eventually becoming a social institution. When children come of age, complete the so-called "social delectation" of breaking free from their parents' strong control (Fei 1999), acquire economic independence, and form their own family unit, choosing whether to continue living with their parents becomes a

Table 5 Predicted probabilities of coresidence with different combinations of parent-child economic resources

\begin{tabular}{|c|c|c|c|c|c|c|}
\hline & & & \multicolumn{4}{|c|}{ Parents' resources } \\
\hline & & & High & Middle & Low & Average \\
\hline \multirow[t]{4}{*}{ Rural subsample } & Children's resources & High & 0.371 & 0.429 & 0.562 & 0.475 \\
\hline & & Middle & 0.432 & 0.546 & 0.667 & 0.614 \\
\hline & & Low & 0.494 & 0.576 & 0.694 & 0.654 \\
\hline & & Average & 0.434 & 0.540 & 0.673 & 0.617 \\
\hline \multirow[t]{4}{*}{ Urban subsample } & Children's resources & High & 0.353 & 0.417 & 0.537 & 0.416 \\
\hline & & Middle & 0.448 & 0.546 & 0.640 & 0.502 \\
\hline & & Low & 0.562 & 0.614 & 0.691 & 0.636 \\
\hline & & Average & 0.417 & 0.566 & 0.643 & 0.527 \\
\hline
\end{tabular}

Note: 1 . When predicted probabilities are computed using Stata, other variables are in effect fixed as the average values. 2. Cases were deleted if children's ISEI was missing 
watershed of the formation of different family systems. The aim of this study is to investigate the relationship between older parents' and their children's socioeconomic resources and the living arrangement of coresidence, examine the mechanism of formation of coresidence at the micro level, and search for traces of change in China's family institution. Based on the review of prior studies, we arrived at the theoretical assumption that the coresidential living arrangement of several generations is no longer the binding cultural ideal in today's China. Using this assumption as a point of departure, we proposed the argument that the choice of living arrangements between older parents and children is determined to a large degree by the economic resources of the two. We derived two hypotheses from the argument and then conducted related empirical analysis using data from the initial wave of the Chinese Family Panel Study in 2010. Overall, the results provided strong support for our research hypotheses.

Our main findings can be summarized as follows. First, coresidence is still the major form of living arrangement for the elderly population in contemporary China. More than half of older parents lived with their children in 2010. The coresidence rate is higher in rural areas than in urban areas. Second, older parents' and children's economic resources are major determinants of the choice to coreside. Parents' and children's socioeconomic resources influence coresidence independently. When both older parents and their adult children are economically disadvantaged, they have the highest probability of living together; on the other hand, when both are economically well off they have the lowest chance of coresiding. Third, the mechanism linking intergenerational economic resources to coresidence applies in both rural and urban areas. However, it has more explaining power in rural areas than in urban areas. ${ }^{10}$

In his seminal work The Institutions for Reproduction, the late sociologist and social anthropologist Fei Xiaotong points out that even in the traditional Chinese society the extended family was not so prevalent, and the families of common peasants were usually rather small. Only the well-to-do who lived in the town, such as merchants, landlords, and local gentries, could afford to have large families (Fei 1999). American sociologist William Goode holds a similar view (1963). More recent studies on the patterns of living arrangements in developing countries also find that the proportion of coresidence is higher among the wealthy than among the poor (Martin 1989). All of these works confirm the notion that the extended family was the cultural ideal in traditional China. When the realization of the extended family is constrained by the limit of resources, people can have their ideal form of living arrangement fulfilled only if they possess a certain amount of wealth (Fei 1999; Ruggles and Heggeness 2008). However, our investigation has uncovered a quite different pattern. It is precisely the economically disadvantaged who are more likely to choose coresidence compared to those who are relatively economically privileged, and the well-to-do prefer to not coreside. These findings corroborate the basic conclusion reached by numerous studies in recent decades, namely that the extended family is no longer a generally accepted cultural ideal. Furthermore, we argue that when coresidence is no longer culturally defined as a worthy personal goal, economic considerations are an important issue in deciding whether to coreside.

The fulfillment of coresidence involves negotiations between two generations in which both economic resources and emotional connections are important factors in the decision process. Since coresidence is a major form of resource sharing between 
two generations, older parents are not necessarily the only beneficiaries. Indeed, we suspect that in many cases, the original intention of living together may not be for the purpose of old-age support. Many adult children do not live with their parents continuously; instead, they may move out of their parental family when they find a job or get married, then move back or take parents into their own homes when the parents are in need of support. However, our results suggest that the better their economic conditions the less likely they will choose coresidence; or conversely the worse the economic conditions the more likely they will choose coresidence (Xie and Zhu 2009; Chang and Yu 2014). The negative relationship between children's economic resources and coresidence suggests that children also benefit economically from coresidence or would be the main beneficiary. In this sense, coresidence should not be taken as the main indicator of old-age support. For older parents, there is also a negative association between economic conditions and coresidence. For those parents who cannot take care of themselves due to advanced age or losing a spouse, coresidence with their children is an important way to improve their quality of life. On the other hand, for those who are economically independent with good functional health, coresidence is not as appealing. All these findings suggest that from either the parents' or the children's standpoint, coresidence in a general sense is largely the result of economic considerations. Given that the extended family is no longer viewed with veneration and aspiration, coresidence may reflect more the desire for mutual assistance between two generations or the binding force of family obligations than anything else. In other words, coresidence has simply become a strategy, a modus vivendi, to deal with various economic problems or to improve quality of life in the family life cycle.

Can our results also be explained by modernization theory? According to this theory, modernization of values and worldviews is an important aspect of this process. Education and modern careers are the important pathways through which people abandon traditional values and accept the values commensurate with modern society. ${ }^{11}$ In other words, it is plausible that the evidence presented in our study may not be strong enough to support the argument that coresidence is driven by economic factors. Changes in values, especially the acceptance of the idea of the nuclear family as a norm in modern society, may be responsible for the differentials in coresidence that we have observed in this study. To test this plausibility at least partially, we adopted two methods in the analyses. First, we added a composite variable that measured traditional values as a control into our multivariate analysis for the purpose of determining whether the net effects of economic resources on coresidence were still statistically significant. Second, our analyses based on the rural and urban areas subsamples assessed to a certain extent the validity of the notion of modernization of ideas. The results showed that after controlling the traditional value variable or conducting multivariate analyses on rural and urban subsamples, the effects of both parents' and children's economic resources still had significant influence on coresidence. More importantly, it is our understanding that analysis of the effects of economic factors on living arrangements at the micro level is not necessarily incompatible with macrolevel modernization theory. The former is more likely a supplement or extension to the former.

At the macro level, living arrangements are affected by cultural, demographic, and social and economic conditions (Guo 2002). Under the assumption of cultural norms and economic development being stable, it is conceivable that the coresidence rate would 
experience a sharp decrease when the parents of the only-child generation reach old age. By the same token, as China's economic development continues unabated, it can be readily inferred from the results of this study that the coresidence rate will decrease. Nevertheless, as discussed above, the increase or decrease of coresidence does not necessarily imply the rise or decline of families' old-age support system. Even when older parents and their children live apart, it is highly likely that they will continue to maintain close economic, instrumental, and emotional connections with each other (Unger 1993). In the light of the findings from previous studies on family relations and old-age support in China, this is another conclusion we can draw from this study.

\section{Endnotes}

${ }^{1}$ Modernization theory is a huge system of ideas that incorporates some of the viewpoints on social change of almost all founding members of sociology (Ding 1988). The theory has been established, modified, and expanded by researchers from multiple disciplines and deals with societal changes involving political, economic, cultural, education, and family systems since industrialization.

${ }^{2}$ Sociologist Arland Thornton offers a thorough critique of the single linear growth paradigm in his book Reading History Sideways: The Fallacy and Enduring Impact of the Developmental Paradigm on Family Life (2005).

${ }^{3}$ To be fair, Goode does not propose that the conjugal family is one of the causal factors of industrialization but only argues that industrialization and the conjugal family are historically connected and theoretically compatible to each other. Furthermore, Goode (1963) suggests that the conjugal family may be one of the determinants of industrial development.

${ }^{4}$ Factors of population structure such as age structure (number of children within a family) and life expectancy and generation length (the years both older parents and children are alive) all exert influence on proportions of different family structures and living arrangements (Zeng 1986, 1991). However, since the focus of this study are factors that influence living arrangements at the micro level, not the coresidence rate, we chose not to discuss this aspect.

${ }^{5}$ Even in the traditional setting, the moral force of the cultural norm for the extended family was not as strong as some would imagine. For instance, it was rather common in traditional rural China that villagers chose to divide extended families into smaller ones once children grew up and married (Cohen 1976; Fei 1999).

${ }^{6}$ For detailed information regarding CFPS, refer to $\mathrm{Yu}$ Xie et al. The Chinese people's livelihood development report 2013 (2013) or visit the Web site of the survey (http://www.isss.edu.cn/cfps/).

${ }^{7}$ In regard to recent descriptions of the occupational structure of China using the ISEI measure, see Qiang Li's article "Inverted T-shaped social structure and social strain” (2005). The reason we did not use income as one of the measures of children's socioeconomic status is because the CFPS 2010 data did not include any information on the income of noncoresiding children. Although the survey is exceptionally detailed about the respondent's family life, for noncoresiding family members, it asked only about their occupation and education but not income.

${ }^{8}$ The Cronbach alpha of the composite variable is 0.59 , indicating reasonably good internal consistency. 
${ }^{9}$ We realize that in comparison with the 2010 census data, the proportion of coresidence appears to be a bit too high (see Wang 2014). We suspect the reason is that the proportion of three-generation families in the original sample is higher than one would expect (Xie et al. 2013, 320-324). On the other hand, other studies using probability sample data also show that the coresidence rate is around $60 \%$ (Chang and Yu 2014). In addition, we removed the families in which the elderly respondents were childless. All these may have contributed to the slightly higher coresidence rate that we report in Table 1.

${ }^{10}$ The reason may lie in the fact that in comparison with cities, the level of economic development in rural areas is relatively low and therefore the marginal utility of economic resources is relatively high. The deeper reason, we suggest, is that in rural areas the family household is a unit of production as well as consumption, and it therefore demonstrates more instrumental rationality than the urban family household (Popkin 1979).

${ }^{11}$ We are particularly thankful to one anonymous reviewer for his/her suggestion that modernization of values may also provide a plausible explanation for the pattern that we report in this article.

\section{Acknowledgments}

Financial support for this project was provided by the Institute for Empirical Social Science Research, Xi'an Jiaotong University. We are also grateful to Li Liming at Xi'an Jiaotong University; Tang Can, Zhang Yi, Wu Xiaoying, and Wang Yuesheng at Chinese Academy of Social Sciences; Wang Tianfu at Tsinghua University; and anonymous reviewers for their valuable comments and suggestions. The research team of the Chinese Family Panel Studies at Peking University provided assistance on data analysis on several occasions. We take responsibility for all possible errors in the article.

\section{Authors' contributions}

JC designed the framework of the study, conducted research design, and drafted the manuscript. QC carried out the research by contributing to statistical analysis, literature review, and the revision of the manuscript. The final draft was revised and approved by both authors.

\section{Competing interests}

The authors declare that they have no competing interests.

Received: 21 July 2016 Accepted: 6 September 2016

Published online: 17 September 2016

\section{References}

Becker, Gary S. 1976. The economic approach to human behavior. Chicago: University of Chicago Press.

Becker, Gary S. 1991. A treatise on the family, Enlargedth ed. Cambridge: Harvard University.

Bengtson, Vern L. 2001. Beyond the nuclear family: The increasing importance of multigenerational bonds. Journal of Marriage and Family 63: 1-16.

Burgess, Ernest W. 1916. The function of socialization in social evolution. Chicago: University of Chicago Press.

Caldwell, John C. 1976. Toward a restatement of demographic transition theory. Population Development Review 2: $321-66$.

Caldwell, John C. 1982. Theory of fertility decline. New York: Academic Press.

Chang, Ying-Hwa, and Rouh-rong Yu. 2014. The persistence and change of family structure: A comparison of the living arrangement of the aged between Chinese mainland southeast and Taiwan region. Sociological Studies 29: 167-88.

Chen, Jieming. 1998. Investment and old age support: A causal analysis of intergenerational exchange in urban areas. Social Science in China 6: 131-49.

Chen, Jieming. 2010. China's old age support system: Traditional culture, family boundary and intergenerational relations. Journal of Xi'an Jiaotong University (Social Sciences) 30: 44-50, 61

Cohen, Myron L. 1976. House united, house divided: The Chinese family in Taiwan. New York: Columbia University Press.

Coleman, James S. 1986. Social theory, social research, and a theory of action. American Journal of Sociology 91: 1309-35.

Cowgill, Donald O. 1972. A theory of aging in cross-cultural perspective. In Aging and modernization, ed. D.O. Cowgill and L.D. Holmes, 1-13. New York: Appleton-Century-Crofts.

Davis-Friedmann, Deborah. 1985. Intergenerational inequalities and the Chinese revolution: The importance of agespecific inequalities for the creation and maintenance of social strata within a state-socialist society. Modern China 11: 177-201.

Davis-Friedmann, Deborah. 1991. Long lives, Expandedth ed. Stanford: Stanford University Press.

Ding, Xueliang. 1988. The origin and theoretical framework of modernization theory. Social Science in China 1: 65-78. 
Fei, Xiaotong. 1983. The issue of old age support in the transition of family structure-discuss the transition of family structure again. Journal of Peking University (Humanities and Social Sciences) 3: 6-15.

Fei, Xiaotong. 1999. The institutions for reproduction. Peking: Commercial Press.

Feng, Xiaotian. 2009. The residential pattern of urban parents and their only child. Academia Bimestris 5: 24-30.

Goldscheider, Frances K., and Calvin Goldscheider (eds.). 1989. Ethnicity and the new family economy: Living arrangements and intergenerational financial flows. Boulder: Westview Press.

Goldthorpe, John H. 2006. On sociology, vol. 1. Palo Alto: Stanford University Press.

Goode, William J. 1963. World revolution and family patterns. Glencoe: Free Press.

Goody, Jack. 1990. The oriental, the ancient and the primitive. Cambridge: Cambridge University Press.

Guo, Zhigang. 2002. The Chinese advanced old people's residential patterns and the influential factors. Population Research 26: 37-42.

Hajnal, J. 1982. Two kinds of preindustrial household formation systems. Population and Development Review 8: 449-94.

Hedström, Peter, and Richard Swedberg. 1998. Social mechanisms: An introductory essay. In Social mechanisms: An analytical approach to social theory, ed. Peter Hedström and Richard Swedberg, 1-31. Cambridge, MA: Harvard University.

Inglehart, Ronald. 1997. Modernization and postmodernization. Princeton: Princeton University Press.

Laslett, Peter. 1972. The household and family in past time. Cambridge: Cambridge University Press.

Li, Qiang. 2005. Inverted T-shaped social structure and social strain. Sociological Studies 20: 55-73.

Logan, John, and Fuqin Bian. 2003. Idea and practice of coresidence between the urban parents and their marriage children. Chinese Journal of Population Science 2: 46-52.

Logan, John R., Fuqin Bian, and Yanjie Bian. 1998. Tradition and change in the urban Chinese family: The case of living arrangements. Social Forces 76(1998): 851-882.

Macfarlane, Alan. 1986. Marriage and love in England 1300-1840. Oxford: Basil Blackwell Inc

Macfarlane, Alan. 1987. The culture of capitalism. Oxford: Basil Blackwell Inc.

Martin, Linda G. 1989. Living arrangements of the elderly in Fiji, Korea, Malaysia, and the Philippines. Demography 26: $627-43$

Ogburn, William F. 1932. Recent social trends. New York: McGraw-Hill.

Parish, William L., and Martin K. Whyte. 1978. Village and family in contemporary China. Chicago, IL: University of Chicago Press.

Parsons, Talcott. 1949. The social structure of the family. In The family: Its function and destiny, ed. Ruth N. Anshen, 173-201. New York: Harper.

Parsons, Talcott, and Robert F. Bales. 1955. Family, socialization and interaction process. Glencoe: Free Press.

Popkin, Samuel. 1979. The rational peasant: The political economy of rural society in Vietnam. Berkeley: University of California Press.

Ruggles, Steven. 2007. The decline of intergenerational coresidence in the United States, 1850-2000. American Sociological Review 72: 964-89.

Ruggles, Steven, and Misty Heggeness. 2008. International coresidence in developing countries. Population and Development Review 34: 253-81.

Shorter, Edward. 1977. The making of the modern family. New York: Basic Books Inc.

Stone, Lawrence. 1980. Family, sex and marriage in England, 1500-1800, abridgedth ed. London: Harper \& Row.

Thornton, Arland. 2005. Reading history sideways: The fallacy and enduring impact of the developmental paradigm on family life. Chicago: University of Chicago Press.

Tsui, Ming. 1989. Changes in Chinese urban family structure. Journal of Marriage and the Family 51: 737-47.

Unger, Jonathan. 1993. Urban families in the eighties: An analysis of Chinese surveys. In Chinese families in the Post-Mao era, ed. Deborah Davis and Steven Harrell, 25-49. Berkeley: University of California Press.

Wang, Yuesheng. 2006. The changing family structure in contemporary China: An analysis. Social Science in China 6: 96-108.

Wang, Yuesheng. 2014. A study on the types of family with elderly in urban and rural china based on the sixth census data. Chinese Journal of Population Science 1: 20-32.

Whyte, Martin K., and William L. Parish. 1984. Urban life in contemporary China. Chicago: The University of Chicago Press.

Xie, Yu, and Haiyan Zhu. 2009. Do sons or daughters give more money to parents in urban China? Journal of Marriage and Family 71: 174-86.

Xie, Yu, Xiaobo Zhang, Jianxin Li, Xuejun Yu, and Qiang Ren. 2013. The Chinese people's livelihood development report 2013. Peking: Peking University Press.

Xu, Qi. 2013a. An exploring matrilocal coresidence: The influence of modernization, population transition and practical needs. Population \& Economics 201: 47-55.

Xu, Qi. 2013b. The influence of children's needs on intergenerational coresidence. Chinese Journal of Sociology 33: 111-30.

Yan, Shengming, Jieming Chen, and Shanhua Yang. 2001. The effects of living arrangements on children's support of their parents. Social Science in China 6: 130-40.

Yang, C.K. 1959. The Chinese family in the communist revolution. Cambridge: MIT Press.

Yang, Juhua, and Lulu Li. 2009. Intergenerational dynamics and family solidarity: A comparative study of mainland China, Japan, Korea and Taiwan. Sociological Studies 24: 26-53.

Yang, Shanhua, and Changmei He. 2004. The ethic of responsibility and the family support in Beijing —an analysis based on the data from the survey carried out in 1999 for the demand of the aged in Beijing. Journal of Peking University (Humanities and Social Sciences) 41:71-84.

Zeng, Yi. 1986. Changes in family structure in China: a simulation study. Population and Development Review 4: 675-703.

Zeng, Yi. 1991. Family dynamics in China: a life table analysis. Madison: University of Wisconsin Press. 